\title{
Parental Deployment and Youth in Military Families: Exploring Uncertainty and Ambiguous Loss*
}

\author{
Angela J. Huebner
}

Jay A. Mancini

\author{
Ryan M. Wilcox
}

Saralyn R. Grass

Gabriel A. Grass**

\begin{abstract}
Parental deployment has substantial effects on the family system, among them ambiguity and uncertainty. Youth in military families are especially affected by parental deployment because their coping repertoire is only just developing; the requirements of deployment become additive to normal adolescent developmental demands. Focus groups were used to inquire about uncertainty, loss, resilience, and adjustment among youth aged 12-18 that had a parent deployed, most often to a war zone. The nature of uncertainty and ambiguous loss was explored. Response themes included overall perceptions of uncertainty and loss, boundary ambiguity, changes in mental health, and relationship conflict. These accounts suggest that ambiguous loss is a useful concept for understanding the experiences of these youth and for structuring prevention and intervention efforts.
\end{abstract}

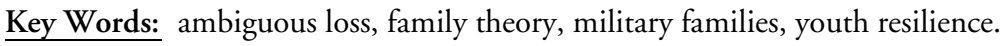

Loss occurs in numerous contexts and under a variety of conditions. Often, what is common to these contexts and conditions is uncertainty. An example of a complex situation of uncertainty and loss is found in the life of an adolescent who has a parent deployed to a war zone in the post-9/11 era because the situation has the usual elements of a catastrophic situation, more normal elements of being deployed, and the potential tragic elements of terrorism. The work of Boss on ambiguous loss provides an important framework for exploring how adolescents experience and respond to parental deployment (Boss, 1999, 2004, 2006). Her framework is instructive because of its grounding in family stress and resilience theory; its extant applications to various individual, family, and community situations; and its relevance for prevention and intervention programs. An ambiguous loss is by definition uncertain, vague, unclear, and indeterminate (Boss, 1999). A family member may be physically absent but psychologically present, or a family member may be physically present but psychologically absent; both of these situations thwart people's desire for certainty and may become an obstacle in healthy patterns of development. This kind of loss may also be uncertain as to its duration or even whether or not loss has occurred. Ambiguous loss can be associated with a number of family situations, including chronic physical or mental illness, missing persons, adoption, or divorce (see Boss, 2004, p. 555, for a chart of the range of family loss conditions).

\section{Deployment, War, Terrorism, and Uncertainty}

Loss and uncertainty are because of circumstances and situations, as well as perceptions people have about those situations. Beyond the built-in uncertainties of the situation, individuals process uncertainty in different ways, thus each person's actual experience of loss may vary.

*This research was supported by a grant from the Military Family Research Institute at Purdue University. We also appreciate the support of the Department of Defense Quality of Life Office and the National Military Family Association.

**Angela J. Huebner is an Associate Professor in the Department of Human Development at Virginia Tech, Northern Virginia Graduate Center, 7054 Haycock Road, Falls Church, VA 22302 (ahuebner@vt.edu); Jay A. Mancini is a Professor in the Department of Human Development at Virginia Tech, 303 Wallace Hall, Blacksburg, VA 24061 (mancini@vt.edu); Ryan M. Wilcox is a Research Assistant in the Department of Human Development at Virginia Tech, 7054 Haycock Road, Falls Church, VA 22043 (rwilcox@vt.edu); Saralyn R. Grass is a Research Project Coordinator in the Episcopal Children’s Services, 100 Bell Tel Way, Suite 100, Jacksonville, FL 32216 (ssap@vt.edu); Gabriel A. Grass is a Grants Specialist in the Nemour’s Partnership for Children’s Health, 4600 Touchton Road East, Building 200, Ste 500, Jacksonville, FL 32246 (ggrass@nemours.org). 
From a situational perspective, the only certainty about the deployment of a service member during war in an era of terrorism is uncertainty from beginning to end. This feeling of uncertainty may begin when families begin to wonder about if-or when - their husband/father's or wife/mother's unit will be mobilized and then deployed (Pincus, House, Christenson, \& Adler, 2004; Waynick, Frederich, \& Scheider, 2005). Although families are almost always given a date for when a unit will be deployed, this often changes. It is not uncommon for families to accompany their deploying member to the send off point only to find out that the date has been changed, causing families to repeat their whole goodbye ritual (Waynick et al., 2005). This scenario illustrates the emotional ambiguity that begins even before the service member leaves.

This ambiguity continues at both a practical and an emotional level when the service member actually deploys or leaves the family for duty in a war zone. At a practical level, families must reorganize their daily routines so they can function without the physical presence of the deployed member (Pincus et al., 2004). For active duty service members, such reorganizations may be commonplace; for National Guard and Reserve Families, this may be a new experience. In both cases, families may wonder how permanent these changes will be. In addition, ambiguity is increased as they may feel both guilt and pride at being able to function in the absence of the deployed member (Pincus et al.).

At an emotional level, ambiguity is evidenced by thoughts of safety and harm. The family of the wardeployed military member knows he/she is in harm's way, but at any one time cannot know how close to conflict they may be, especially in an era when terrorist insurgents are the enemy. Although the parent is physically absent, they are likely to be in regular communication with family because of cell phone and Internet technology (Waynick et al., 2005). During the time when virtual contact is occurring, the deployed family member is presumed to be safe, thereby reducing uncertainty. However, once this contact ceases, safety becomes again unknown. Adolescents are well aware of the possibility of losing a parent permanently through death or of a parent returning home maimed or incapacitated. This awareness is reinforced on a daily basis because of explicit media coverage of war events (Huebner \& Mancini, 2005). Together, these factors cumulate into a situation of unpredictability and uncertainty for families and their adolescents. Uncertainty is further exacerbated because of wondering when a deployed family member will return home (redeployment). Although a return date is often provided, it is not uncommon for this date to be changed as deployments are extended (Waynick et al.). This ambiguity about returning contributes to the emotional roller coaster families experience.

Researchers have linked parental deployment (usually defined as father deployment) to several youth outcomes. These include depression (Hillenbrand, 1976; Jensen, Martin, \& Watanabe, 1996; Levai, Kaplan, Ackerman, \& Hammock, 1995), acting out or negative behavioral adjustment (Hillenbrand; Levai et al., 1995; Yeatman, 1981), poor academic performance (Hiew, 1992; Yeatman), and increased irritability and impulsiveness (Hillenbrand). Results of a study on children's reaction to the Desert Storm deployment included increased tearfulness, increased discipline problems at home (particularly among boys), and increased demands for attention (Rosen, Teitelbaum, \& Westhuis, 1993). Research conducted with military families also demonstrates that the mental health of the at-home parent (usually the mother) is very influential in determining child adjustment (Jensen et al., 1996; Medway, Davis, Cafferty, Chappell, \& O’Hern, 1995; Rosen et al., 1993). Jensen and Shaw (1996) suggested that the effect of absences are mediated by several factors including predeployment family relationships, the age and gender of children, the meaning of the absence to the family, the extent of danger to which the military member is exposed, and how the remaining spouse deals with the absence.

Adolescents are already facing multiple normative stressors including puberty and school transitions (Simmons \& Blyth, 1987). Parental deployment contributes to additional stressors such as relocation (especially if both parents are deployed or the adolescent is from a single-parent family), changes in family roles, and daily routines (Pincus et al., 2004). These changes may be especially pronounced for adolescents in National Guard and Reserve Families for whom extended deployments previously were not common. These additional stressors may task the adolescents' limited coping resources beyond their capacity.

In a war situation in which a deployed parent is alive but not present with the child, exactly what is the loss? It appears that little has been written about uncertainty in the lives of adolescents as it relates to 
the experience of ambiguous loss. Admittedly, this is a unique exploration of the concept of ambiguous loss because, in the case of deployment to an active war zone, adolescents are dealing with a situation in which the absent parent may return home unharmed. Nonetheless, at the very least, the loss of parental presence during deployment means that key events in youth's lives are missed. Even more importantly, the fact that a parent does return safely does not diminish the stress that was experienced during the actual absence. For this reason, our interest was in examining how the adolescent copes during the time when they are uncertain of the status of the absent parent. Although the duration is frequently longer, this situation is not unlike that faced by adolescents who have parents employed in other dangerous occupations (e.g., firefighters and police officers), which also necessitate extended absence from home (e.g., Regehr, Dimitropoulos, Bright, George, \& Henderson, 2005).

\section{Theoretical Framework}

Of particular relevance for explaining our study findings is the ambiguous loss theory (Boss, 1999, 2004, 2006). According to Boss (2006, p. 1), "The premise is that ambiguity coupled with loss creates a powerful barrier to coping and grieving, and leads to symptoms such as depression and relational conflict that erode human relationships." Boss' framework in effect asserts that connections between family members persist somewhat independent of whether they are present or absent. A poignant phrase Boss uses is "there but not there" or "here but not here." This is a very descriptive phrase suggesting the complexity of family connections. A significant part of this theory is the context in which families "live," whether they are economic hard times or parental deployment. As such, context is a variable that is typically beyond one's control. This theory posits an important element that may cause distress is an inability to resolve the circumstance. In the case of deployment, the circumstance cannot be resolved by family members. Consequently, the cause of these loss feelings is out of their control.

One result of ambiguous loss is boundary ambiguity, or in Boss' (2006, p. 12) words, "not knowing who is in or out of your family or relationship." Boss (1977, p. 142) stated,
“. . . a physical absence may not be synonymous with the symbolic or psychological absence of the person from the family system." Accordingly, how boundary ambiguity is resolved can be a more critical indicator of family functioning than actual physical presence. Boundary ambiguity is particularly salient for families in which a parent is frequently away for work (Zvonkovic, Solomon, Humble, \& Manoogian, 2005), as is often the case in military families. The context of family life may be confusing as members struggle to organize and reorganize roles and responsibilities as members flow in and out (Boss, 1999).

Our research model was derived from the literature on family context, risk, and resilience (Boss, 1999, 2006; Hill, 1949; McCubbin \& Patterson, 1983; Patterson, 2002; Patterson \& McCubbin, 1987). The organization of the research plan corresponded with the Double ABC-X framework where " $A$ " refers to the deployment (i.e., potential ambiguous loss), "B" refers to existing resources, " $C$ " refers to the perception of " $A$," and " $X$ " refers to outcomes, including behavior and mental health changes, changes in roles and responsibilities, and relationships with others. For our sample, the most observable stressor ("A") was the parent's deployment to an active war zone, though we also recognize that for adolescents, there are a number of normative developmental stressors as well (e.g., fitting in with their peer group) that may coincide with the deployment. The combination of unusual stressors and normative stressors fits with the pileup part of the Double ABC-X stress and resilience model (McCubbin \& Patterson).

We used the ambiguous loss framework to organize the responses of youth to uncertainty associated with parental deployment. We have chosen to extract a subset of our data that reflect Boss' ambiguous loss theory through the Double $\mathrm{ABC}-\mathrm{X}$ model lens, even though in many ways, virtually all study elements in some regard speak to uncertainty. Four categories of data are presented that illustrate the experience of ambiguous loss as perceived by adolescents with deployed parents. Consistent with effects discussed by Boss (2002), these categories are (a) overall perceptions of uncertainty and loss, (b) boundary ambiguity, (c) changes in mental health, and (d) relationship conflict. All reflect a family system that is reorganizing itself because of the absence of a key family member. 


\section{Method}

\section{Selection of Focus Group Participants}

Adolescents were identified for study participation via their attendance at one of several camps sponsored by the National Military Family Association (NMFA) and through State 4-H Military Liaisons (a partnership between Cooperative Extension and the U.S. Military). Admission to the NMFA camps was restricted to those youth who currently had a parent deployed. Information about the camps was distributed through military contacts in various forms (flyers, email, newsletters, etc.) to deploying parents with adolescents. Given that participation in the NMFA camps was not mandated, our sample frame was somewhat unique in that it included youth whose parents were active in securing their young person's attendance. It is important to note that the camps were free thus eliminating any bias of socioeconomic status that might occur. Each youth provided proof of parental consent prior to participation. To build in some diversity among participants, focus groups were conducted in five states: Washington, Hawaii, Texas, Virginia, and Georgia.

Study participants $(n=107)$ were between 12 and 18 years. About $46 \%$ of the participants were girls and $54 \%$ were boys. Ethnicity was reported as 61\% White, 17\% African American, 7\% Hispanicl Latino, 3\% Pacific Islander, 1\% Native American, and $10 \%$ biracial. Service representation included 39\% Army, 3\% Navy, 10\% Air Force, 4\% Marines, 23\% National Guard (Army and Air Force), and 13\% Reserves (all branches). All participants had experienced parental deployment, and in almost all cases, a parent was deployed to Iraq or Afghanistan.

\section{Data Collection Procedures}

Data were gathered in an in-depth semistructured focus group interview that lasted $90 \mathrm{~min}$. The 107 participants were spread across 14 focus groups. The focus groups consisted of both boys and girls. In most cases, the groups were divided according to age, with younger adolescents together in one group and older adolescents together in another group. Each focus group was audiotaped and then transcribed. The focus group format was chosen for several reasons.

Focus groups are often considered less intimidating to individual participants than individual interviews (Madriz, 2000). Given that our sample was comprised of adolescents who were being asked to discuss potentially emotional issues, we tried to be sensitive to issues of intimidation and discomfort. Additionally, we hoped that the group format would diminish the perceived power differential between youth and adults (Eder \& Fingerson, 2001). One advantage of the focus group format is that it allows participants to interact with each other rather than just the facilitators. Indeed, in our focus group experience, adolescents often responded directly to each other. As one youth mentioned areas of concern or issues, others were quick to provide support or validation of their feelings and experiences. It was not our experience that focus group members were intimidated or embarrassed by the conversation.

In contrast, Morgan (2001) suggested that researchers should use care in employing a focus group format with adolescents because, depending on the topic, the result may actually be more of a reflection of peer culture than true opinions. Although some reflection of peer culture may have been illuminated during the focus groups, we believe it was minimal. Specifically, adolescents were interviewed in mixed-gender groups. Further, prior to attending the camp, most of the youth did not know each other. In many cases, the focus group was the first time they had come together for any type of group discussion. In addition, the facilitators strived to find a balance between participants' spontaneous interactions with each other and providing opportunities for all voices to be heard. Because camp participation was contingent on having a deployed parent, study participants were prepared to discuss such issues and were not singled out as "different" because of their parent's deployment status. Finally, as suggested by Eder and Fingeson (2001), the focus groups were integrated into a larger activity (the camp).

On a practical level, focus groups allow researchers to gather large amounts of data in limited amounts of time. Given our audience of adolescents, we were concerned about maintaining attention. Additionally, in most cases, we were trying to fit our research into a preexisting camp schedule. 


\section{Data Analysis}

Atlas.ti software (Scientific Software, 2004) was used to manage the data. Data analysis was conducted using the constant comparative method (Corbin \& Strauss, 1998; Strauss \& Corbin, 1990). To begin the process, open coding on two of the focus group transcripts was conducted independently by four members of the research team. A comparison of these codes revealed few discrepancies among coders. Such intersubjective agreement is an indicator of the trustworthiness of the data (Lincoln \& Guba, 1985). Discrepancies that did occur were discussed and consensus was achieved, resulting in a list of core categories (Strauss \& Corbin). These core categories were subsequently applied to the remaining 12 transcripts and the process of crosscoding and discrepancy resolution was repeated. Reports of each primary code were reviewed and subsequent subcategories were developed using a similar consensus building strategy.

\section{Results}

To illustrate uncertainty and ambiguous loss, we present four main categories of results: (a) overall perceptions of uncertainty and loss, (b) boundary ambiguity, (c) changes in mental health, and (d) relationship conflict. The themes in each category are described and followed by exemplar quotes. In addition, we provide the number of youth whose statements were included in each respective category.

\section{Overall Perception of Uncertainty and Loss}

An important element for ultimately understanding responses to deployment of a parent is the emotional interpretation by the adolescent. Adolescents who experience the same event will each respond differently to that event, becoming more or less adaptable, or being more or less upset. We asked, "How did you feel when you found out your parent was being deployed?" Words like "nervous," "worried," "confused," "mad," "lonely," “isolated," "sad," "afraid," and "shocked" were consistently mentioned by 53 of the participants. On occasion, an adolescent used the term "proud." One even said, "I'm glad he's there to protect us." Overall, very few used positive terms to describe their feelings.
Comments also reflected conflicting feelings such as feeling both angry and proud or changing feelings such as moving from denial to recognition of the reality of loss.

Adolescents also made comments reflecting a sense of "loss" of an important person who provided security and assistance. This loss was described in terms of what was missing in everyday life activities. Examples included not having the parent to help with homework, participate in activities, or provide guidance. It was common for adolescents to make comments reflecting their confusion or ambiguity about the future. Not surprising, a frequent initial reaction to the deployment was uncertainty about whether or not the adolescent would see the deployed parent again. The following quotes are illustrative:

I just didn't know how long they would be gone and when they would come back, because plans change a lot. And we just didn't know like how long we would have to go without our parent.

I wouldn't say I feel mad, but it's kind of confusing about why he would want to do and put himself in that position.

I was angry at everybody. I'm like a big daddy's girl, so I was really sad he was going away. And I was scared something bad might happen to him.

I didn't think anything at first. I just kind of blew it off and didn't really know it was going to be that long. And then when it started happening, started sinking in, it was hard.

I feel enraged. Just means that he got taken away from me, they took my dad away from me.

\section{Boundary Ambiguity}

Boundary ambiguity appeared to be an issue for many youth with deployed parents. This ambiguity was evidenced as adolescents discussed the changes in their roles and responsibilities that occurred when their parent was deployed. For some adolescents in the study, deployment had been experienced more than once. Others were experiencing it for the first time. In some cases, these changes provoked stress in youth; in others, deployment was viewed as opportunity for growth. We asked, "How does your life change when a parent is deployed?" Quotes are 
divided into three areas in which boundary ambiguity was apparent: routines, responsibilities, and reintegration of a parent upon return. Sixty participants discussed changes in roles and responsibilities, 50 discussed themes consistent with routine changes, and 12 discussed issues of reintegration.

\section{Roles and responsibilities.}

... when my dad's not there, I'm not, you know, the child anymore. I have to like kind of almost fill in for the other parent because the only thing my mom really cares about is that I'm ready to baby sit.

I kind of have to be the strong one with my mom and then my younger sister.

... Now [that deployment has occurred] me and [sister] are basically stuck doing all the chores. We're stuck doing the living room, the kitchen, the vacuuming, the mowing. . .

\section{Routine changes.}

I usually do a lot of school sports . . but now with this [deployment] I don't have transportation very often to go to those activities and I usually have to skip them.

... When your dad's not home you don't get to go fishing, go paint balling, go skiing, waterskiing, water tubing, playing sharks, and stuff.

... Then we usually have family dinners where we sit down all together. But since he's [dad] been gone, we usually just kind of eat at different times or we just like go into the living room. . .

\section{Reintegration of returning parent.}

And that like it was a lot harder for us too, you know, to get into the routine of having him back than it was for him to leave . . Because there were responsibilities taken up by each of us and then when dad came home, we didn't have the responsibilities anymore, but we were used to them and so that caused a change also. And so it's just like, okay, what do we do now? We can't go back to being who we were because we're not that anymore. We have to move forward, but it's also something you have to do as a whole family.
Like when my dad got back, it was kind of hard because he had been away from the family for so long and we were all able just to depend on mom so it was kind of hard letting him back into the family. And then also the experiences he got over there were all like fighting and stuff. Sometimes you would hear him shouting in his sleep.

\section{Changes in Mental Health: Depression \& Anxiety}

Thirty-four participants made statements reflecting changes in mental health. Specifically, adolescents reported several signs consistent with depression including lost interest in regular activities, isolation, changes in sleeping and eating patterns, sadness and crying, and in two cases, psychiatric hospital admissions (American Psychiatric Association, 2005). They also reported a higher level of anxiety as evidenced by ruminations about what the deployed parent was doing and concerns over safety.

I can't go to sleep. Because they're up and doing something and you can't like, you're thinking about what they are doing.

The worst time is when the phone rings because you don't know who is calling. They could be calling, telling you that he got shot or something.

I could tell my mom was getting like really depressed and since she wouldn't talk, I wouldn't talk. And so around the house everyone was just kind of depressed for a little while and you could tell because they didn't speak a lot.

\section{Relationship Conflict}

Participants provided clear examples of greater intensity in family emotions, their own uncontrolled "lashing out" responses, changes in their relationship with the nondeployed parent (almost always their mother), and difficulties when the deployed parent returned home.

Family emotional intensity. Thirty-five participants gave examples of increased emotional intensity in the home. Most examples centered on interactions with their mother and concerns over her level of stress. Some also included concerns over other family members' ability to cope with the situation. 
[It's hard] not having a dad to depend on for like 2 years, and now my mom is always upset when we talk about him. I was angry at everybody. . . . Just because I'm suffering because my dad's gone; I mean my sisters are going to be too. So I can't just be like leave me alone, you know, because I'm not doing well because Dad's gone. I can't say that. I can't do that. I have to, you know, deal with it and help them deal with it because they are younger.

When my dad was getting deployed, it's just really hard because my sisters whine a lot ... and every night they always cry. I feel like crying along with them, but I just hold it in.

Lashing out responses. When asked about how they deal with stress, 27 participants said that they tended to "lash out" at others for things that normally would not upset them. These lashing out behaviors were primarily verbal, with increased arguments and yelling. Adolescents that reported this behavior often also talked about feeling like they needed to stuff their emotions to protect other family members and friends.

Sometimes I-like, not because I mean to or anything-but I get snappy, sometimes because the stress just leaps onto other people. I don't really deal with it. I try not to . . . I just kind of hide it and I don't really deal with it until it gets to the breaking point where I'm just like, ugh! And I can't take it anymore.

... Because when you're under as much stress as most of the people are that have parents gone ... all your emotions, it just mixes up and you might just go off on someone if they say something wrong .... and I'll just get mad for no reason ... .

Changes in parent-child relationship. Parents and adolescents are influenced by each other in both positive and negative ways (Ge, Conger, Lorenz, Shanahan, \& Elder, 1995; McGue, Elkins, Walden, $\&$ Iacono, 2005). Parents role model both positive and negative behaviors, which will be reflected in their adolescents. With deployment, family responsibilities often become entirely the responsibility of the at-home parent, in most cases a mother. Forty- one adolescents reported noticing changes in their mother's behaviors and emotions. These included a shorter temper, being stressed out, and exhibiting behaviors consistent with signs of depression (e.g., more emotional, sleeping, and absentmindedness). These changes had an impact on the relationship between mothers and adolescents.

My mom acts different when my dad's gone. It's like she's not her normal self. She's kind of like stressed out and stuff and her stress out affects me too.

It's just a lot more stress on her. Like she holds her stress pretty well, but she just like, if me and my sister are acting up, she gets mad a lot easier.

[When my dad's gone] my mom breaks out in this really emotional thing, a really emotional like problem.

When my dad is gone-the entire time he was gone-my mom, she just didn't try hard.

Reunion and reintegration. Forty-two adolescents who had experience with reunions mentioned the difficulties of reintegrating the formerly absent parent back into the family. This difficulty centered in part on the fact that routines and responsibilities had changed and the returning parent was not aware of the changes, expecting everything to be the same as it was when he or she left. It also centered on the fact that many adolescents reported having become more attached to their mother during their father's absence. Adolescents also mentioned that they had matured a great deal during the time that their parent was deployed but felt like the deployed parent did not recognize or appreciate these changes, leaving the adolescent confused about what they should be doing.

Well when my dad left, everything's going one way, and when he comes back he's starting right where he left so . . . There's just a big clash and that starts lots of problems ... Like he forgets that he's been gone for like a year or six months. So he thinks we're a lot younger and while he was gone we matured a lot over the year. And he's still trying to treat us the way we were treated a year ago. 
It's just hard when they come back; it's hard to set the rules back how they were.

Dad was gone so you didn't have that guy-to-guy bonding. But mom had to pretty much do everything. Kind of got more attached to my mom. It was kind of a problem when dad got back because you're more attached to one parent now.

\section{Summary}

Our findings support the efficacy of the theory of ambiguous loss for understanding adolescent adjustment during parental military deployment. For the most part, adolescents in our study exhibited a range of emotions associated with deployment reflecting uncertainty about its meaning and how it would affect them. Their early and ongoing responses to deployment revolved around not knowing what would happen in the future, either with their deployed parent's welfare or their own. Behavioral changes on the part of adolescents included a greater tendency to act out toward others and a lower threshold for emotional outbursts. At an emotional level, manifestations of depression and anxiety were common and related to ongoing uncertainty about the status of the deployed parent. These emotions and behaviors could be interpreted as early manifestations of ambiguous loss.

Over the course of deployment, adolescents were required to assume and then relinquish various roles and responsibilities regarding family life, thereby adding confusion to their place in the family system. In many respects, it seems that reunion and reintegration of the deployed parent was more difficult than the actual absence. Additionally, adolescents were acutely aware of changes in the nondeployed parent, including their emotional state and personal resilience. Effects on the family system were manifested in conflicts with the nondeployed parent and increased overall emotional intensity among family members (i.e., parent, focus group participant, and siblings).

\section{Implications}

\section{Research and Theory}

Our study is exploratory in many respects, especially as it pertains to a focus on uncertainty and ambiguous loss. The merits of this concept and its surrounding theory are supported by many of the responses these adolescents provided, which reflect ambiguous loss. Given that our sample was small $(n=107)$ and limited to adolescents who were attending summer camps, we hesitate to generalize our findings beyond this limited group. Nevertheless, the reports of these adolescents are consonant with related research on military families (see Martin, Mancini, Bowen, Mancini, \& Orthner [2004], for details on military family demographics and family issues), as well as with what family theories suggest (Boss, 1999, 2006). Deployment could, however, be considered a special case of an ambiguous loss situation, and we have not fully explored if or how its nuances separate it from other ambiguous loss situations.

Another theoretical perspective that explains contextual influences on families and on adolescents as they experience loss is social organization theory (Mancini, Bowen, \& Martin, 2005). This perspective, in part developed from research on military families (Bowen, Mancini, Martin, Ware, \& Nelson, 2003), focuses on network structures, social capital, and community capacity, all elements of individual, family, and community resilience. This perspective could be useful in developing community level support for youth and families experiencing situations of ambiguous loss. Our recent research on a diverse group of adolescents suggests the merits of taking such a layered network approach to issues of risk and resilience (Huebner \& Mancini, 2003; Mancini $\&$ Huebner, 2004).

\section{Professional Practice}

Boss (2006) has advanced a framework for helping families deal with ambiguous loss that centers on fostering resilience. The framework includes (a) finding meaning, (b) tempering mastery, (c) reconstructing identity, (d) normalizing ambivalence, (e) revising attachment, and (f) discovering hope. We use this framework to inform responses to the areas of ambiguous loss explored within this article (i.e., perceptions of uncertainty and loss; boundary ambiguity; changes in mental health; and relationship conflict). In dealing with an adolescent population, it is important for clinicians and youth development professionals to recognize the wide range of physical, cognitive, and emotional development that occurs during this period of life and 
to tailor interventions and programs accordingly (National Research Council and Institute of Medicine, 2002).

Perceptions of uncertainty and loss. How can we help young people deal with uncertainty and loss? Boss' (2006) notion of making meaning is informative. Finding meaning is an attempt to make sense out of a particular event or situation and is important because the way people think about an event shapes the way they attempt to deal with it. How can we help adolescents with deployed parents make meaning of their situation? Boss suggested that meaning making often comes from interactions with peers. Such ongoing discussion should occur in a collaborative setting in which youth themselves can set the tone for what is to be discussed. Adult moderators could gently ask the participants to describe their deployed parent and what it is that he or she is doing. The meaning they make may change through the course of the interaction. It may also be helpful to ask youth how others in the community view their deployed parent's work. Responses to this question may be direct or they may be in the form of a picture, song, or poem because youth express their feelings in diverse ways. Adolescents' responses provide a window into the meaning they attribute to the situation. Do they view their parent's actions as noble and self-sacrificing for a greater good, as selfish and irresponsible, or some place in between? Providing opportunities for such discussions and helping youth to reframe the negative situations could be particularly useful.

Boundary ambiguity. How can we help adolescents deal with boundary ambiguity? As illustrated in this study, boundary ambiguity can result from experiencing changes in roles and responsibilities, which in turn can relate to changes in identity. Boss' notions of reconstructing identity and tempering mastery are helpful for addressing this issue. In relation to ambiguous loss, Boss (2006, p. 116) defined identity as "knowing who one is and what roles he or she will play in relation to others in a context of family and community." Accordingly, identity develops out of interaction. For adolescents, identity development is an important and evolving task (Erikson, 1968). It may be confusing for an adolescent to renegotiate identity within the family when their own sense of self is not yet stable. Comments from our focus group participants such as, "he made me the man of the house" and
" . . . when my dad's not there I'm not the child anymore," are illustrative of the potential confusion adolescents may be feeling.

Mastery refers to having control (Boss, 2006). In situations of ambiguous loss, mastery may be impossible given that the situation is external and thus out of the adolescent's control. Coming to terms with the reality that "life is not fair" is a difficult concept for adults and more so for early adolescents because they are still firmly planted in the concrete operational mode of thought and just beginning to delve into the idea of abstraction (Piaget, 1977). For this age group, life is about absolutes-absolutes of right and wrong. A primary goal for the helping professions is to help adolescents understand that life is sometimes unfair but not always unfair.

One way to achieve this goal is to help youth recognize which situations they have control over and which they do not. Providing assistance to youth so they externalize the "blame" for their parent's absence while at the same time helping them to take control over situations they do have some say about becomes pivotal. For example, adolescents cannot control the length of the deployment nor their parent's safety, but they can control how they themselves react to their new situation. Their new roles, responsibilities, and routines can provide an excellent opportunity for gaining new skills and thus increasing feelings of mastery and contribution to the family. Clinicians can help adolescents to recognize past successes and encourage them to build on their strengths. Youth development professionals can offer skill-building classes in specific areas of interest (e.g., sibling child care, cooking, lawn care, gardening). Adults, including parents, other family members, and helping professionals, can assist adolescents with issues of boundary ambiguity by making expectations for new roles explicit; and then, consistent with the notion of gaining mastery, ensure that adolescents have the requisite skills to be successful in their new roles. There should also be some discussion of whether these changes in roles will be temporary or permanent so that adolescents are prepared for future changes.

Changes in mental health. How do we help youth deal with changes in mental health? One obvious solution is to increase awareness of mental health issues. Specifically, provide psychoeducational programs about the signs and symptoms of depression to youth and the adults with whom they 
come into contact (e.g., parents, teachers, youth development professionals). Additionally, youth should be encouraged to develop wellness plans that include strategies for dealing with stress and anger. Given the mutual influence of parent and adolescent distress (Ge et al., 1995), parents should also be encouraged to take care of their own mental health and to model healthy behavior to their youth. Because the family system is experiencing change, professional intervention should also be system oriented and multilayered.

Relationship conflict. How can we help adolescents deal with relationship conflict? Boss (2006) described notions of normalizing ambivalence and revising attachments that are useful. Ambiguous loss can lead to feelings of ambivalence toward the missing person and others in the family, and if left unidentified, can lead to such negative outcomes as anxiety, somatic symptoms, and eventual guilt (Boss). Focus group participant reports of changes in mental health and increased family conflict suggest that adolescents need assistance in externalizing the situation and normalizing their feelings. They also need help in understanding that it is acceptable to feel conflicted. They can be encouraged to accept that part of their ambiguity comes from trying to hold two opposite ideas in their head at the same time-that my parent is fine and that my parent may be injured or dead. We echo Boss' advice about the importance of adults being truthful with adolescents about the uncertainty of the situation. Additionally, adolescents may need assistance in acquiring the skills needed to express their thoughts and emotions constructively.

When an important person to whom people are attached disappears, "survivors often turn away from the world and withdraw into apathy" (Boss, 2006, p. 165). According to Boss (2006, p. 166), "healthy adaptation to a missing attachment is to gradually disconnect while at the same time reconnecting to available and caring persons." This is an important application to the situation of an adolescent with a deployed parent because some level of disconnection and reconnection must occur for adolescents to function well with their siblings, the parent still at home, and at school. We were surprised to discover that many adolescents in our sample were using a withdrawal response as their primary mode of coping with deployment stress (Huebner \& Mancini, 2005). When a parent is absent he/she will not be supervising homework, taking the youth to activities, and the like. In contrast, other caring adults, including the remaining parent, can effectively take on these tasks. Adolescents are still in the process of honing communication and social skills, so reconnecting is not likely to come easily, even with the other parent. We also discovered (reported elsewhere) that some adolescents were not as close to the remaining parent to begin with and therefore had to strive to make that connection stronger (Huebner $\&$ Mancini). The potential positive influence of other caring adults in the lives of adolescents with a deployed parent can be substantial but require intentionality on the part of parents and professionals. Ongoing support networks, rather than crisisonly support networks, that include adults other than the parents, adults in other military families, adults associated with military family support systems, and adults mobilized by civilian community organizations are important.

\section{Conclusion}

Parental deployment has substantial effects on the family system and particularly on adolescents. They experience ambiguous loss and uncertainty, and effects of this kind of loss are displayed in ways that potentially impede successful adolescent development. We reported on a range of outcomes among adolescents who were experiencing parental deployment. In all instances, these undesirable outcomes are amenable to prevention and intervention efforts. The theory of ambiguous loss and its associated prevention and intervention framework (Boss, 2006) aids in describing the loss situation, interpreting responses to loss, understanding family system changes, and charting a course of support to adolescents and their families. Responses of adolescents to parental absence under threat conditions is complex and reflects the complexity of this kind of ambiguous loss, a loss situation imbued with uncertainty and fear, clearly out of control of the family itself, and potentially life altering. This complexity, however, is not beyond the reach of professional practices intent on minimizing ambiguity and on maximizing individual, youth, family, and community resources to assist multiple family members, including the deployed parent, to reorganize their everyday lives and to build resilience. 


\section{References}

American Psychiatric Association. (2005). Diagnostic and statistical manual of mental disorders (4th ed., text revision). Washington, DC: Author.

Boss, P. (1977). A clarification of the concept of psychological father presence in families experiencing ambiguity of boundary. Journal of Marriage and the Family, 39, 141-151.

Boss, P. (1999). Ambiguous loss: Learning to live with unresolved grief. Cambridge, MA: Harvard University Press.

Boss, P. (2002). Ambiguous loss in families of the missing. The Lancet Supplement, 360, s39-s40.

Boss, P. (2004). Ambiguous loss research, theory, and practice: Reflections after 9/11. Journal of Marriage and the Family, 66, 551-566.

Boss, P. (2006). Loss, trauma, and resilience: Therapeutic work with ambiguous loss. New York: W.W. Norton.

Bowen, G. L., Mancini, J. A., Martin, J. A., Ware, W. B., \& Nelson, J. P. (2003). Promoting the adaptation of military families: An empirical test of a community practice model. Family Relations: Interdisciplinary Journal of Applied Family Studies, 52, 33-44.

Corbin, A., \& Strauss, J. (1998). Basics of qualitative research: Techniques and procedures for developing grounded theory (2nd ed.). Thousand Oaks, CA: Sage.

Eder, D., \& Fingerson, L. (2001). Interviewing children and adolescents. In J. Bugruium \& J. Holstein (Eds.), Handbook of interview research: Context \& method (pp. 181-201). Thousand Oaks, CA: Sage.

Erikson, E. (1968). Identity, youth, and crisis. New York: Norton.

Ge, X., Conger, R., Lorenz, F., Shanahan, M., \& Elder, G. (1995). Mutual influence in parent and adolescent psychological distress. Developmental Psychology, 31, 406-419.

Hiew, C. C. (1992). Separated by their work: Families with fathers living apart. Environment and Behavior, 24, 206-225.

Hill, R. (1949). Families under stress: Adjustment to the crises of war, separation and return. Oxford, England: Harper.

Hillenbrand, E. D. (1976). Father absence in military families. The Family Coordinator, 25, 251-258.

Huebner, A. J., \& Mancini, J. A. (2003). Shaping structured out-of-school time use among youth: The effects of self, family, and friend systems. Journal of Youth and Adolescence, 32, 453-463.

Huebner, A. J., \& Mancini, J. A. (2005). Adjustments among adolescents in military families when a parent is deployed. Final report to the Military Family Research Institute and Department of Defense Quality of Life Office. Retrieved December 18, 2005, from Virginia Polytechnic Institute and State University, Department of Human Development Web site: http://www.unirel.vt.edu/news/Huebner_Mancini_teens_ study.pdf

Jensen, P., \& Shaw, J. (1996). The effects of war and parental deployment upon children and adolescents. In R. Ursano \& A. Norwood (Eds.), Emotional aftermath of the Persian Gulf War: Veterans, families, communities, and nations (pp. 83-109). Washington, DC: American Psychiatric Press.

Jensen, P. S., Martin, D., \& Watanabe, H. (1996). Children's response to separation during Operation Desert Storm. Journal of the American Academy of Child and Adolescent Psychiatry, 35, 433-441.

Levai, M., Kaplan, S., Ackerman, R., \& Hammock, M. (1995). The effect of father absence on the psychiatric hospitalization of Navy children. Military Medicine, 160, 103-106.

Lincoln, Y., \& Guba, E. (1985). Naturalistic Inquiry. Newbury Park, CA: Sage.

Madriz, E. (2000). Focus groups in feminist research. In N. Denzin \& Y. Lincoln (Eds.), Handbook of qualitative research (pp. 835-850). Thousand Oaks, CA: Sage.
Mancini, J. A., Bowen, G. L., \& Martin, J. A. (2005). Community social organization: A conceptual linchpin in examining families in the context of communities. Family Relations: Interdisciplinary Journal of Applied Family Studies, 54, 570-582.

Mancini, J. A., \& Huebner, A. J. (2004). Adolescent risk behavior patterns: Effects of structured time-use, interpersonal connections, self-system characteristics, and socio-demographic influences. Child and Adolescent Social Work Journal, 26, 647-668.

Martin, J. A., Mancini, D. L., Bowen, G. L., Mancini, J. A., \& Orthner, D. K. (2004, April). Building strong communities for military families (NCFR Policy Brief.) Minneapolis, MN: National Council on Family Relations.

McCubbin, H. I., \& Patterson, J. M. (1983). The family stress process: The double ABCX model of adjustment and adaptation. Marriage \& Family Review, 6, 7-37.

McGue, M., Elkins, I., Walden, B., \& Iacono, W. (2005). Perceptions of the parent-adolescent relationship: A longitudinal investigation. Developmental Psychology, 41, 971-984.

Medway, F. J., Davis, K. E., Cafferty, T. P., Chappell, K. D., \& O'Hern (1995). Family disruption and adult attachment correlates of spouse and child reactions to separation and reunion due to Operation Desert Storm. Journal of Social and Clinical Psychology, 14, 97-118.

Morgan, D. (2001). Focus group interviewing. In J. Bugruium \& J. Holstein (Eds.), Handbook of interview research: Context \& method (pp. 141-159). Thousand Oaks, CA: Sage.

National Research Council and Institute of Medicine. (2002). Community programs to promote youth development. In J. Eccles \& J. Gootman (Eds.), Committee on community-level programs for youth: Board on child youth, and families, division of behavioral and social sciences and education (pp. 45-64). Washington, DC: National Academy Press.

Patterson, J. M. (2002). Integrating family resilience and family stress theory. Journal of Marriage and the Family, 64, 349-360.

Patterson, J. M., \& McCubbin, H. I. (1987). Adolescent coping style and behaviors: Conceptualization and measurement. Journal of Adolescence, $10,163-186$.

Piaget, J. (1977). The development of thought: Equilibration of cognitive structures. New York: Viking.

Pincus, S., House, R., Christenson, J., \& Adler, L. (2004). The emotional cycle of deployment: A military family perspective. Retrieved December 21, 2005, from http://www.hooah4health.com/deployment/familymatters/ emotionalcycle.htm\#

Regehr, C., Dimitropoulos, G., Bright, E., George, S., \& Henderson, J. (2005). Behind the brotherhood: Rewards and challenges for wives of firefighters, Family Relations, 54, 423-435.

Rosen, L., Teitelbaum, J., \& Westhuis, D. (1993). Children's reactions to the Desert Storm deployment: Initial findings from a survey of Army families. Military Medicine, 158, 465-469.

Scientific Software. (2004). Atlas.ti. Berlin, Germany: Author.

Simmons, R., \& Blyth, D. (1987). Moving into adolescence. New York: Aldine De Gruyter.

Strauss, A., \& Corbin, J. (1990). Basics of qualitative research: Grounded theory procedures and techniques. Thousand Oaks, CA: Sage.

Waynick, T., Frederich, P., \& Scheider, D. (2005, October). Enabling military families to survive the traumas of war. Presentation at the 63rd meeting of the American Association of Marriage and Family Therapists, Kansas City, MO.

Yeatman, G. W. (1981). Parental separation and the military child. Military Medicine, 146, 320-322.

Zvonkovic, A., Solomon, C. R., Humble, A. M., Manoogian, M. (2005). Family work and relationships: Lessons from families of men whose jobs require travel. Family Relations, 54, 411-422. 